\title{
BULLYING E CYBERBULLYING: QUANDO OS VALORES MORAIS NOS FALTAM E A CONVIVENCIA SE ESTREMECE
}

\author{
BULLYING Y CYBERBULLYING: CUANDO LOS VALORES MORALES NOS \\ FALTAN Y LA CONVIVENCIA SACUDI
}

\author{
BULLYING AND CYBERBULLYING: WHEN THE MORAL VALUES ARE \\ LACKING AND THE COEXISTENCE IS SHAKING
}

\author{
Luciene Regina Paulino TOGNETTA ${ }^{1}$ \\ Darlene Ferraz KNOENER ${ }^{2}$ \\ Sanderli Ap. Bicudo BOMFIM ${ }^{3}$ \\ Sandra Trambaiolli DE NADAI ${ }^{4}$
}

RESUMO: Este estudo teórico objetiva evidenciar a ausência de conteúdos morais em situações de bullying e cyberbullying, destacando, em contrapartida, a necessidade de compreender esse fenômeno da violência como um problema moral. Em meio a um contexto de relações interpessoais violentas vivenciado nas instituições de ensino, seja de forma presencial ou virtual, urge destacar as evidências das investigações atuais sobre esse tema que apontam para a superação do problema por meio de processos que priorizem a composição de um ambiente que favoreça a formação moral e a convivência ética. Uma vez que a escola desempenha um papel significativo na construção da moralidade do sujeito, é necessário que haja, em cada instituição de ensino, a sedimentação de um projeto de convivência ética, de modo a explicitar o pacto de todos os seus personagens com a prevenção à violência. A literatura atual aponta a necessidade de tais programas e projetos de convivência ética que sejam intencionais, sistematizados e contínuos, proporcionando espaços de protagonismo para os alunos a fim de que exercitem e vivenciem valores morais para que estes tomem lugar central em sua personalidade, justamente por destacar o quanto tais valores estão ausentes naqueles que agridem, bem como muitas vezes naqueles que recebem ou testemunham a agressão.

PALAVRAS-CHAVE: Bullying. Cyberbullying. Valores. Convivência. Formação

RESUMEN: Este estudio teórico visa clarear la ausencia de contenidos morales en situaciones de bullying y ciberbullying resaltando, por otro lado, la necesidad de entender este fenómeno de violencia como un problema moral. En medio a un contexto de relaciones violentas entre personas que viven en instituciones educativas, aunque de forma presencial

${ }^{1}$ Universidade Estadual Paulista (Unesp), Araraquara - SP - Brasil. Professora do Departamento de Psicologia da Educação Pedagoga. Líder do GEPEM - UNESP/UNICAMP. E-mail: lrpaulino@uol.com.br

${ }^{2}$ Universidade Estadual Paulista (Unesp), Araraquara - SP - Brasil. Mestranda em Educação Escolar. Membro do GEPEM - UNESP/UNICAMP. E-mail: darlene.knoener@ gmail.com

${ }^{3}$ Universidade Estadual Paulista (Unesp), Araraquara - SP - Brasil. Mestranda em Educação Escolar. Membro do GEPEM - UNESP/UNICAMP. E-mail: sanderli.bicudo@gmail.com

${ }^{4}$ Universidade Estadual Paulista (Unesp), Araraquara - SP - Brasil. Mestranda em Educação Escolar. Membro do GEPEM - UNESP/UNICAMP.. E-mail: sctnadai@ hotmail.com 
o virtual, insta-se clarear las evidencias de investigaciones actuales sobre este tema, que apuntan para una superación del problema a partir de procesos que valoran la composición de un ambiente que favorezca la formación moral y la convivencia ética. Una vez que la escuela se compromete a un papel significativo en la construcción de la moralidad de la persona, es necesario que haya, en cada institución educativa, la fijación de un proyecto de convivencia ética, de modo a explicitar lo papel de todos los personajes visando la prevención de la violencia. La literatura actual apunta la necesidad de estos programas y proyectos de convivencia ética que sellan intencionales, sistemáticos y continuos, de modo a ofrecer espacios de protagonismo a los alumnos, con el objetivo de que ejerciten y vivencien valores morales para que estos tomen lugar central en suyas personalidades, justamente para destacar la importancia de valores ausentes aquellos que agreden, bien como, muchas veces, en los que reciben o testigüen la agresión.

PALABRAS-CLAVE: Bullying. Cyberbullying. Valores. Convivencia. Formación.

ABSTRACT: This theoretical study aims to highlight the absence of moral content in situations of bullying and cyberbullying, emphasizing, on the other hand, the need to understand this phenomenon of violence as a moral problem. In a context of violent interpersonal relations experienced in educational institutions, whether face-to-face or virtual form, it is urgent to highlight the evidences of the current investigations on this subject that aim to overcome the problem through processes that prioritize the composition of an environment that favors moral formation and ethical coexistence. Since the school is very important in building the morality of its students, there must be, in every educational institution, the consolidation of a project of ethical living, in order to make explicit the pact of all its characters with the prevention of violence. The current literature indicates the need for programs and projects of ethical coexistence that are intentional, systematized and continuous, providing spaces of protagonism of the students, in order to exercise and experience moral values so that they will be priority in their personality precisely by highlighting how much these values are absent in those who attack as well as often in those who receive or witness the aggression.

KEYWORDS: Bullying. Cyberbullying. Moral values. Coexistence. Teacher's training.

\section{Introdução}

Pensar o bullying como um problema moral nos remete a interpretá-lo como uma falta exatamente do valor em jogo quando o problema se apresenta: o respeito. Como um valor moral, o respeito sempre foi alvo de importantes discussões que perpassaram pela história das ciências.

Sem a pretensão de simplificar a dimensão grandiosa dos estudos dessa temática e considerando que trataremos o próprio valor em jogo como a "moral" que nos falta quando 
uma agressão gratuita como o bullying ou cyberbullying acontece, poderemos constatar que estudos da Psicologia ganham importância para entendermos esse fenômeno humano. LevyBruhl, ainda na Filosofia, já destacava a necessidade de pensar uma oposição entre o "ser e o dever ser". La Taille nos lembra o pedido desse autor para que a moral fosse objeto de um estudo naquilo que nascia: a Psicologia (LA TAILLE, 2002), que poderia nos dar a chance de entender a guerra estudando o guerreiro (TOGNETTA; LA TAILLE, 2008).

Foi Piaget o pioneiro em buscar evidências dessa grande temática que se buscava compreender no campo da Psicologia. Na verdade, Piaget não dedicou seus estudos exclusivamente ao desenvolvimento moral, mas estudou, pesquisou e escreveu sobre a gênese do conhecimento na criança e, portanto, do conhecimento humano. Assim, ao tratar da temática da moral, Piaget não teve como se distanciar dos estudos do desenvolvimento cognitivo e da energia que move toda e qualquer ação: a afetividade. Não estudou os comportamentos movidos pelos afetos como o fez Freud, mas o aspecto afetivo presente e implícito em toda ação, inclusive, portanto, na moral. Ele equacionaria, assim, a moral como um conjunto de regras para viver bem em duas tendências - uma sem um contrato entre os envolvidos, a heteronomia, e outra quando há um contrato entre as partes, a autonomia. Seus estudos foram continuados por Kohlberg (psicólogo e pesquisador norte-americano, também de formação kantiana, na década de 1960), que não descartou tais tendências, conduzindo suas investigações com base no paradigma cognitivo-evolutivo construtivista de Piaget, mas dele se tornando refém sem se atentar a aspectos importantes da teoria piagetiana, como a ideia de que tendências morais, e não estágios, designariam o desenvolvimento moral. Contudo, os estudos de Kohlberg juntam-se a outros de mesmas bases epistemológicas (COLBY; DAMON, 1993; TURIEL, 1978), que investem no entendimento da moral destacando os aspectos cognitivos e afetivos presentes nos juízos e ações do homem e mesmo onde estaria a fonte dessa moral (Ricoeur, Taylor). Provocam, assim, ainda hoje, a grande indagação que aqui se destaca: por que se preocupar com o outro? O que "ganhamos" com isso? Ou ainda: o que faz com que nossa escolha seja por um conteúdo moral ou por subjugar o outro?

Certamente, a resposta para as interrogações não é simples e depende, de fato, de nossas crenças sobre a gênese de um valor moral como o respeito, a justiça, a generosidade. Se retomarmos Kant (1974), por exemplo, veremos que a moral propõe princípios universalmente válidos, ou seja, aquilo que for considerado bom deve ser para toda a humanidade, independentemente das diferentes culturas. Esse princípio incondicional e 
universal ele chamou de Imperativo Categórico. Em conformidade com a visão de Kant, Vásquez (1997) afirma que a moral se refere a um sistema de regulamentação das relações entre sujeitos que promove uma determinada forma de comportamento humano válida em todos os tempos e em todas as sociedades. Contudo, o próprio Kant não teria deixado de constatar a necessidade de certa "força de vontade". Ainda que sem explorá-la, como o fez Piaget, essa força pressupõe uma espécie de regulador dos próprios juízos e ações, já que sua existência se confirma quando entendemos que saber do dever ou da obrigatoriedade de uma regra não nos é suficiente para agir moralmente. Há uma motivação interior desdenhada por alguns, mas eleita como necessária por outros para que o investimento aconteça (LA TAILLE, 2006; TOGNETTA; VINHA, 2009).

Ética e moral - mais do que palavras em jogo, um jogo de palavras que percorre o movimento do que é capaz de fazer um "animal moral": ter consciência do dever (moral) e querer um sentido para sua vida (ética) (LA TAILLE, 2006; TOGNETTA; LA TAILLE, 2008). Logo, entende-se que a ética pressupõe uma ação reflexiva, na dimensão do querer, cujas decisões levam em conta a vida individual e o sentido atribuído pelo sujeito à vida em sociedade. Sendo assim, os valores morais podem ser considerados os investimentos que motivam o sujeito a comportar-se de certa maneira e o levam a julgar e justificar a sua própria ação e a dos outros (KNAFO; DANIEL; KHOURY-KASSABRI, 2008; SCHWARTZ, 1992). Segundo Piaget (1994), os valores são investimentos afetivos que movem o sujeito e guiam suas ações. São, como diria Aristóteles (1991), nossas “ações humanizadas" e, portanto, as virtudes, como generosidade, justiça, solidariedade, tolerância, honra, fidelidade, fraternidade, entre outras, assumidas por cada um de nós numa hierarquia que nos indica como desejamos ser vistos ou como vemos sentido em nossas ações.

Mas qual seria sua relação com uma contravirtude como a violência chamada bullying? O fato é que o vício, ou o contrário das virtudes supracitadas, é incorporado às representações de si daqueles que agridem como uma forma de se sentirem bem ou se sentirem respeitados. Faltaria, então, a própria "moral" ou o seu conteúdo - os valores do bem, pouco presentes em suas ações.

\section{Bullying e cyberbullying: a crise moral vai à escola}

Sabemos que o ambiente escolar tem papel relevante na formação moral do sujeito, 
pois é onde, desde criança, o indivíduo envolve-se com regras, interage com seus pares e visualiza modelos de autoridade e conduta (VINHA, 2000; ARAÚJO, 1993; TOGNETTA, 2003; DeVRIES, 1998). Contudo, na prática, em vez de a escola protagonizar relações de cooperação que proporcionem adesão aos valores morais por parte dos sujeitos envolvidos, frequentemente o que se vê são instituições de ensino servindo como palco de atos de violência de ordem verbal, física, moral, sexual, material, virtual e psicológica. Preconceito étnico-racial e religioso, sexismo, "brincadeiras" violentas, exclusão social (COWIE; MYERS, 2016), enfim, intolerância manifestada de diversas formas a qualquer um que não se adéque aos "padrões". Entre as manifestações violentas frequentes nas relações escolares - injustiças, infrações, indisciplina, depredações, provocações (MENIN et al., 2008; TOGNETTA; VINHA, 2010a, 2010b) -, destacam-se o bullying e o cyberbullying.

O bullying é um problema que afeta a vida de milhares de crianças, jovens e até adultos, causando sofrimento psicológico e físico nas vítimas, ocasionalmente terminando em suicídio. É caracterizado especialmente pelo abuso sistemático entre pares, cujas agressões tendem a ser premeditadas, havendo um desequilíbrio de poder entre o autor e a vítima (OLWEUS, 1993, 1997; AVILÉS MARTÍNEZ, 2009a; DEL BARRIO; MARTÍN; ALMEIDA, 2003; TOGNETTA et al, 2010). Trata-se de uma ação imoral em que alguém inflige (ou tenta infligir), intencionalmente, sofrimento ou desconforto sobre outro (OLWEUS, 1997), especialmente pela humilhação e opressão de vítimas inocentes, em que o agressor apresenta um comportamento social impróprio para alcançar seus objetivos: como domínio, o monitoramento de recursos e de popularidade dentro de um grupo de pares. Estudos apontam que entre $10 \%$ e $30 \%$ dos jovens com idade de 9 a 16 anos estão envolvidos como agressores e/ou vítimas (PEPLER et al., 2008), e esses estudos concordam com outros nacionais e internacionais (TOGNETTA; ROSÁRIO, 2012).

De modo semelhante, o cyberbullying é a forma virtual de praticar o bullying. Ambos partilham uma característica básica, que é a violência intencional contra o outro (TOGNETTA; BOZZA, 2012). A diferença está nos métodos de agressão, pois o cyberbullying, além de dispensar a repetição das agressões, uma vez que todo conteúdo postado nas redes sociais tem alcance ilimitado, ainda que tenha sido publicado uma única vez, é reforçado pela possibilidade de anonimato dos autores e a ausência de confronto direto com a vítima. Esses fatores parecem resultar em baixos níveis de empatia afetiva e cognitiva (ANG; GOH, 2010). Pesquisas têm demonstrado que o cyberbullying desinibe condutas que na vida real seriam controladas pelo medo dos castigos ou das leis sociais e que, portanto, 
não levariam ao bullying (AVILÉS MARTíNEZ, 2010). Fante e Pedra (2008) mencionam que estudos realizados na Inglaterra levantaram que em torno de $25 \%$ das meninas são vítimas de cyberbullying pelo celular. Também destacam estudos feitos nos Estados Unidos, onde $20 \%$ dos alunos do ensino fundamental relataram ser alvo dessa forma de violência.

Temos discutido em nossos grupos de pesquisa no Brasil (TOGNETTA; VINHA, 2010a, 2010b; TOGNETTA; VINHA, 2010b; TOGNETTA, 2011; TOGNETTA; ROSÁRIO, 2012) e na Espanha (AVILÉS MARTÍNEZ, 2003; 2006; 2009b; 2010) a evidência de que as ações de bullying e cyberbullying são formas de desrespeito que indicam um déficit moral, especialmente por parte dos que praticam as agressões.

Da mesma maneira, Menesini, Nocentini e Camodeca (2011) destacam que os agressores parecem ser deficientes em cognições, emoções e comportamentos relativos a questões éticas e morais. Acrescentam que eles são competentes em julgar moralmente, mas deficitários em compaixão moral e sensibilidade, demonstrando mecanismos de desengajamento moral, raciocínio egocêntrico, baixos níveis de motivação moral, empatia, vergonha e culpa. Conclui-se, assim, que há uma distância entre o julgamento moral e a ação moral, e que é preciso considerar as dimensões intelectuais (a do dever) e afetivas (a do querer) ao pensar as questões que envolvem o desenvolvimento moral. Esses jovens e adolescentes precisam querer agir bem, e tais atitudes morais precisam fazer parte de seus valores para bem fazê-lo. Como afirma La Taille (2006, p. 51), "somente sente-se obrigado a seguir determinados deveres quem os concebe como expressão do valor do próprio eu, como tradução de sua autoafirmação". Autores de bullying são encontrados em diferentes pesquisas como desengajados moralmente, o que denota o que chamamos de falta de sensibilidade moral (TURNER, 2009; ALMEIDA; CORREIA; MARINHO, 2010; OBERMANN, 2011; SONJA; GUTZWILLER-HELFENFINGER, 2012; THOMBERG; JUNGERT, 2012; WACHS, 2012).

Apesar dos indicadores de relação entre a forma como se constrói um valor e sua conservação na prevenção ao bullying e ao cyberbullying ou seu contrário, entre a ausência de conteúdos morais e o comportamento antissocial (GERBINO; ALESSANDRI; CAPRARA，2008; KNAFO; DANIEL; KHOURY-KASSABRI，2008; TREMBLAY; EWARD, 2005), ainda há poucos estudos a respeito (MENESINI; NOCENTINI; CAMODECA, 2011).

Em relação às agressões no espaço virtual, Menesini, Nocentini e Camodeca (2011) mencionam as pesquisas apresentadas nas obras de Ang e Goh (2010), Pornari e Wood 
(2010) e S. Bauman (2010). Ang e Goh (2010) afirmam que as características específicas do cyberbullying (por exemplo, o anonimato dos autores e a ausência de confronto direto com a vítima) parecem resultar em baixos níveis de empatia afetiva e cognitiva, o que sugere que estes podem desempenhar um papel mais importante no cyberbullying do que no bullying, especialmente para meninos. Pornari e Wood (2010), por outro lado, investigaram mecanismos de retirada moral. Os resultados mostraram que o desengajamento moral está relacionado à agressão tradicional e à ciberagressão.

Gini (2006) afirma que dois modelos diferentes descrevem o agressor, alternativamente, como uma criança carente de habilidades sociais ou como um indivíduo manipulador e frio, que lidera as gangues para alcançar objetivos pessoais. Em um de seus estudos, ele analisou o desempenho de 204 crianças de 8 a 11 anos em um conjunto de histórias que avaliou o entendimento das cognições e emoções, em relação ao seu papel de participantes em bullying. Avaliou, ainda, a compreensão das crianças de emoções morais e propensão para o desengajamento moral. Concluiu que os agressores não apresentam dificuldade na tarefa de cognição moral, e sim menores níveis de empatia e sensibilidade moral.

\section{Agressores: competência moral reforçada. O déficit está na "compaixão moral"}

Uma pesquisa realizada por Pepler et al. (2008) com 871 alunos (466 meninas e 405 meninos), que foram estudados por mais de sete anos, revelou quatro trajetórias nas situações do bullying na escola: 41,6\% quase nunca relataram bullying; 13,4\% relataram níveis moderados no início do período e quase nenhum assédio moral no final; 35,1\% relataram níveis moderados de forma consistente; e 9,9\% reportaram consistentemente altos níveis de bullying. Ou seja, enquanto a maioria dos agressores está envolvida em bullying temporariamente ou desiste dele, cerca de $10 \%$ da população total é composta por indivíduos que são agressores estáveis ou persistentes e podem seguir uma trilha de desvios - mais de 80 indivíduos que poderão prejudicar tantos outros em sua trajetória de vida.

Do ponto de vista social-cognitivo, os agressores são indivíduos caracterizados pela chamada "cognição fria". Têm boa inteligência social, boa teoria das habilidades mentais e maquiavelismo. Além disso, características sociocognitivas podem permitir que agressores antecipem os pensamentos e ações dos outros, para manipular suas crenças e emoções. 
Muitas vezes, eles usam de mecanismos de desengajamento moral, raciocínio mais egocêntrico e outras distorções cognitivas de autosserviço para evitar sentimento de culpa, especialmente em comparação com os indivíduos que dão suporte às vítimas contra o bullying (GINI; POZZOLI; HAUSER, 2011).

Já as vítimas demostram déficits em habilidades sociais, de resolução de problemas sociais, estratégias de enfrentamento, assertividade e regulação emocional (GINI; POZZOLI; HAUSER, 2011).

Os defensores, aqueles que saem da posição de testemunhas da violência entre pares, são indivíduos pró-sociais que intervêm para parar o assédio moral, ajudam e consolam os colegas ou pedem a intervenção dos adultos. Raramente são agressivos, têm compreensão moral, baixo desengajamento moral, elevado sentido de responsabilidade, autoeficácia social e empatia, e desfrutam de um status elevado entre os pares. Têm habilidades sociocognitivas relativamente sofisticadas que se estendem ao domínio moral, apoiadas por uma compreensão bem desenvolvida dos estados de espírito e sentimentos dos outros (GINI; POZZOLI; HAUSER, 2011).

Gini, Pozzoli e Hauser (2011) realizaram uma pesquisa com 719 crianças na faixa etária de 9 a 13 anos, as quais foram classificadas como agressoras, vítimas ou defensoras, a fim de determinar se as diferenças individuais na competência moral e compaixão estão relacionadas a essas funções. O objetivo era responder a três questões: será que os agressores não têm uma compreensão de certo e errado? Será que simplesmente não se importam? Faltalhes alguma combinação desses dois processos?

A hipótese inicial, com base no trabalho com psicopatas adultos, era de que as crianças que apresentam tendência à prática do bullying são, em alguns aspectos, como psicopatas adultos: têm competência moral relativamente sofisticada, mas compaixão moral deficiente. Ou seja, os agressores mostram uma compreensão madura dos fatores que orientam os julgamentos de certo e errado (por exemplo, crenças, impacto sobre o bem maior), mas não conseguem expressar preocupação com as normas morais que são importantes e o impacto que as transgressões têm sobre o bem-estar dos outros.

A ideia era testar dois componentes de moralidade: competência e compaixão. No quesito competência moral, as crianças avaliaram a legitimidade moral de uma ação. Sobre compaixão moral, avaliaram a extensão da retirada de uma infração moral, isto é, a tendência de diminuir ou eliminar autossanções, a fim de justificar o uso de comportamento violento e agressivo, mostrando-se desengajadas. 
A previsão era de que, no domínio da competência moral, agressores e defensores seriam comparáveis, e ambos sobressairiam em relação às vítimas. Em contrapartida, no domínio da compaixão moral, previram que os defensores sobressairiam em relação aos agressores e que vítimas iriam sobressair em relação aos agressores (GINI, 2006).

O estudo foi realizado com crianças na transição entre o final da infância e o início da adolescência, por três razões principais: é um período em que o envolvimento em assédio moral se torna bastante estável; as crianças nessa fase de desenvolvimento internalizaram um conjunto de regras morais; e as habilidades cognitivas permitem que elas raciocinem acerca de situações morais. Os pesquisadores esperavam que as crianças mais velhas tivessem uma competência moral mais elevada.

Participaram da pesquisa 355 crianças do $4^{\circ}$ e $5^{\circ}$ ano do ensino fundamental $(50,1 \%$ de meninas) com idade entre 9 e 10 anos e 364 adolescentes do $7^{\circ}$ e $8^{\circ}$ ano $(47,0 \%$ de meninas) com idade entre 12 e 13 anos.

Em duas sessões, os participantes completaram um instrumento de nomeação dos pares, um conjunto de cenários morais e a escala de desengajamento moral, alternativamente. Foram enviadas para casa cartas de consentimento com uma descrição do estudo pela escola das crianças. Nenhuma das crianças se recusou a participar.

Para identificar agressores, vítimas e defensores foi aplicado um instrumento que permitia que as crianças nomeassem colegas de classe que se enquadravam em cada uma das nove descrições comportamentais de três tipos de bullying. Os itens de nomeação foram divididos em três escalas: agressores (por exemplo: "Em sua sala de aula, quem são os colegas que mais frequentemente batem ou empurram outros colegas?"), vítimas (por exemplo: "Em sua sala de aula, quem são os colegas que mais frequentemente são atacados ou empurrados por colegas de classe?") e defensores (por exemplo: "Em sua sala de aula, quem são os colegas que mais frequentemente defendem outros colegas de ataques?").

No instrumento com cenários morais, foram apresentadas quatro versões (tipos) de 12 cenários diferentes com base em duas crenças morais (negativa versus neutra) e dois resultados (negativo versus neutro), totalizando 48 cenários diferentes. Os participantes leram quatro tipos de cenário e depois julgaram uma ação do protagonista em uma escala de 1 (muito ruim) a 7 (muito bom). Os tipos de cenário constam do quadro 1. 


\section{Quadro 1 - Tipos de Cenário}

\begin{tabular}{c|l|l} 
Tipo 1 & Dano Bem-Sucedido & $\begin{array}{l}\text { O protagonista realizou uma crença negativa com a intenção } \\
\text { de prejudicar e a ação conduziu a um resultado negativo. }\end{array}$ \\
\hline Tipo 2 & Tentativa de Dano & $\begin{array}{l}\text { O protagonista realizou uma crença negativa com a intenção } \\
\text { de prejudicar, mas a ação não gerou um resultado negativo. }\end{array}$ \\
\hline Tipo 3 & Danos Acidentais & $\begin{array}{l}\text { A crença era neutra (não pretendia nenhum mal), mas a ação } \\
\text { resultou em um dano. }\end{array}$ \\
\hline Tipo 4 & Não Dano & Tanto a crença quanto os resultados foram neutros.
\end{tabular}

Fonte: Autoria própria

Para testar os níveis de compaixão moral foi utilizado um instrumento baseado nos oito mecanismos de desengajamento moral propostos por Bandura (2015), que os descreve como processos sociocognitivos pelos quais uma pessoa normal pode julgar o outro e se afastar de uma ação moral, servindo como ferramentas que desinibem e libertam o indivíduo de autocensura e potencial culpa. Foi usada uma versão de 14 itens da escala de desengajamento moral de Caprara, Pastorelli e Bandura (1995), especificamente projetada e validada para crianças em idade escolar. As crianças classificaram a força de sua aprovação ou rejeição de exoneração moral de conduta prejudicial em uma escala de 5 pontos $(1=$ discordo totalmente, $5=$ concordo totalmente). Escores mais altos indicam uma maior tendência para se envolver em um ou mais desses mecanismos (exemplos de itens: "Algumas crianças merecem ser tratadas como animais", “As crianças não podem ser responsabilizadas por seu mau comportamento se seus amigos as pressionaram a fazê-lo").

Os resultados do primeiro instrumento, de nomeação de pares, demonstraram que as vítimas foram igualmente distribuídas entre meninos e meninas. Já o grupo dos agressores foi mais representado por meninos, e o grupo dos defensores, pelas meninas. Foram atribuídas 409 crianças a um dos seguintes grupos de papel: agressores $(n=103)$, vítimas ( $n$ $=117)$ e defensores da vítima $(\mathrm{n}=189)$. Devido às ausências, 49 crianças não participaram na sessão 1, e 61, na sessão 2. Foram excluídas do grupo vítimas/agressoras, devido ao pequeno tamanho da amostra. Crianças $(\mathrm{n}=310)$ que não receberam um papel definido, porque não se encaixavam nos critérios de classificação, não foram incluídas nas análises que compararam grupos de função.

No instrumento de cenários morais, as crianças julgaram as Tentativas de Dano como sendo piores que os Danos Acidentais, revelando a importância das crenças e intenções em 
relação aos resultados. Convergente com esses resultados, é compatível encontrar crianças muito mais jovens que consideram os resultados finais mais pesadamente que os estados mentais, de tal modo que os Danos Acidentais são percebidos como piores que as Tentativas de Dano, visto que seu critério de responsabilidade pelos dados, como diria Piaget (1994), já se constitui numa responsabilidade objetiva que leva em conta a intenção das ações.

Houve um efeito significativo em relação ao do tipo de cenário, indicando que, independentemente da idade, os participantes julgaram moralmente Dano Bem-Sucedido como a pior situação e Não Dano como a melhor. Danos Acidentais foram julgados como moralmente piores do que Tentativas de Dano. Análises revelaram que os julgamentos dos participantes não diferiram por idade na condição de Danos Bem-Sucedidos. Como esperado, as crianças mais jovens julgaram Danos Acidentais como significativamente mais negativos do que adolescentes iniciais. $O$ padrão oposto emergiu para a condição Tentativa de Dano, que foi considerada mais errada pelos participantes mais velhos.

Quanto à análise do desengajamento moral, os resultados demonstraram que os agressores foram os que mais concordaram com as afirmações típicas de desengajamento moral (como o exemplo dado anteriormente: "Algumas crianças merecem ser tratadas como animais"). Em seguida, o grupo mais desengajado foi o das vítimas e, por último, o dos defensores, que, em sua maioria, discordavam dos itens.

Os resultados complementaram pesquisa realizada anteriormente sobre as competências sociocognitivas e morais de crianças que intimidam colegas, mostrando que os agressores são hábeis em entender os sinais sociais (por exemplo, estados de espírito de outras pessoas, crenças e intenções), explorando essa capacidade para sua própria vantagem (GINI, 2006; SUTTON; SMITH; SWETTENHAM, 1999). Os agressores, ao menos a partir do final da infância, não têm o atraso no desenvolvimento sociomoral que caracteriza outros jovens antissociais (GIBBS, 2010) e, em comparação com os defensores bem ajustados, eles são igualmente capazes de julgar a permissibilidade moral das ações prejudiciais baseados em crenças e intenções do ator, e melhor do que vítimas.

Logo, os agressores revelaram competência moral regular para julgar. O desvio está na importância atribuída por eles a esse conhecimento, especialmente em termos de motivar o comportamento moralmente adequado. Demonstraram ainda deficiências significativas em relação a sentimentos e carinho, pois possuem raciocínio egocêntrico (MENESINI; NOCENTINI; CAMODECA, 2003) e níveis mais altos de desengajamento moral (GINI, 2006; TOGNETTA; AVILÉS MARTÍNEZ; ROSÁRIO, 2016). Nesta última investigação 
citada, Tognetta, Avilés Martínez e Rosário encontraram cenários parecidos. Na pesquisa com 2.600 sujeitos brasileiros, que utilizou um instrumento construído pelos autores para mensurar tanto o engajamento moral quanto o desengajamento moral de sujeitos adolescentes diante de situações hipotéticas de bullying, não foi encontrada uma diferença significativa entre ser "vítima de bullying" e engajar-se ou desengajar-se moralmente, ou seja, vítimas de bullying podem ser tanto engajadas como desengajadas. Contudo, em relação aos agressores, estes são tanto "menos engajados" como "mais desengajados", demonstrando o que Bandura et al. (1996) já acenava para o que pode explicar esses fatos. Segundo ele, seria como se a mente do agressor deixasse de acessar o conhecimento que traz para julgar cenários morais. Por conseguinte, a falta de consciência moral facilitaria o uso e a justificativa da violência para alcançar seus fins egoístas (BANDURA et al., 1996), evidenciando traços insensíveis, como a falta de culpa e vergonha, a falta de empatia e a indiferença. São ausentes, portanto, o que chamamos de "sentimentos morais" já lembrados por Piaget (TOGNETTA; LA TAILLE, 2008). O que mais nos chama atenção nessa pesquisa, porém, é o fato de que as testemunhas, divergindo de pensamentos do senso comum de que seriam indiferentes, se destacam sendo mais engajadas que os demais personagens.

Assim, o deslocamento necessário a ser pensado na superação do problema parece se remeter também e mais precisamente, visto a abrangência maior de espectadores do que de outros personagens envolvidos desde as pesquisas de Olweus $(1993,1997)$ até hoje, aos espectadores. Estes são, de fato, agentes de mudanças no sentido de inspirar boas práticas, cobrar, denunciar e ajudar aqueles que, por razões inúmeras, não conseguiram ainda aderir a um valor moral ou à autoconfiança necessária para a vida em sociedade. Ainda que essa constatação possa nos indicar uma grande possibilidade de superação do problema na escola, destacaremos ainda outras pesquisas que tentaram indicar a falta de valores morais em situações de bullying e cyberbullying.

Menesini, Nocentini e Camodeca (2011) realizaram um estudo com o objetivo de investigar aspectos morais e valores humanos em situações de bullying tradicional e cyberbullying, a fim de detectar diferenças entre os dois fenômenos e testar o papel de comportamentos imorais e desengajados na mediação das relações entre valores pessoais e envolvimento em bullying. A amostra foi composta por 390 adolescentes de diferentes escolas de ensino médio com idade entre 14 e 18 anos, sendo $50 \%$ do grupo composto por meninas. 
Eles utilizaram o sistema de valores desenvolvido por Schwartz (1992) e validado em mais de 70 culturas. Ele é baseado em dez valores caracterizados por diferentes objetivos e resumidos no seguinte: Poder (com o objetivo de status social elevado por meio de dominação e controle de recursos); Realização (aquisição de sucesso por meio da competência de acordo com os padrões sociais); Hedonismo (busca do prazer e da satisfação); Estimulação (desejo de mudança, desafio e emoção); Autodireção (independência de pensamento e ação); Universalismo (compreensão, tolerância e proteção do bem-estar das pessoas e da natureza); Benevolência (cuidado com o bem-estar das pessoas com as quais se está em contato social); Tradição (respeito e aceitação dos costumes tradicionais da cultura ou religião); Conformismo (evitando ações e impulsos que violem as normas sociais); e Segurança (necessidade de uma estrutura social: segurança, harmonia e estabilidade).

De acordo com Schwartz (1992), esses dez valores básicos produzem uma estrutura integrada em torno de um modelo de dois eixos, em que valores adjacentes compartilham objetivos comuns, ao passo que valores opostos têm objetivos divergentes. Essa estrutura pode ser resumida em duas dimensões: autoaprimoramento contra a autotranscendência e abertura a mudanças contra a conservação. Na primeira dimensão (autoaprimoramento versus autotranscendência), poder e realização são contrários ao universalismo e à benevolência. Na segunda dimensão (abertura a mudanças versus conservação), estimulação e autodireção se opõem a segurança, conformismo e tradição. Finalmente, a dimensão do hedonismo compartilha elementos de abertura a mudanças e autoaprimoramento.

Assim, valores diferentes se contrapõem ao comportamento agressivo e violento. Uma vez que os valores de universalismo e benevolência (autotranscendência) promovem o bem-estar e a tolerância para com outras pessoas, eles se correlacionam negativamente com o comportamento violento e agressivo (GERBINO; ALESSANDRI; CAPRARA; 2008; KNAFO, 2003; KNAFO; DANIEL; KHOURY-KASSABRI, 2008). O contrário também acontece: os valores de autoaprimoramento, representados por poder e realização, têm sido muitas vezes associados positivamente a comportamento violento e assédio moral. Já os valores de abertura a mudanças (autodireção e estimulação) foram associados a comportamentos de risco, como busca de sensações, comportamento antissocial e agressão. Os valores de conservação apoiam o uso de comportamentos socialmente aceitáveis. E, finalmente, os adolescentes que mantêm altos níveis nos valores de conformismo e tradição são menos inclinados a adotar comportamentos antissociais e bullying. 
Menesini, Nocentini e Camodeca (2011) acreditam que os níveis de adesão aos valores morais podem influenciar os adolescentes no envolvimento em comportamentos agressivos. No caso dos autores de bullying, verificaram menor pontuação nos valores de autotranscendência (bem-estar alheio) do que os autores de cyberbullying, uma vez que estes últimos podem apresentar empatia nos relacionamentos interpessoais reais, apesar de participarem de agressões virtuais, pois não presenciam o sofrimento da vítima. Logo, autores de bullying revelam níveis mais altos de falhas no comportamento moral do que os agressores virtuais. Em contrapartida, os autores de cyberbullying têm maior pontuação em autorrealização e abertura a mudanças (atenção voltada para si, para obtenção de sucesso, poder, domínio e status social), por serem capazes de controlar os outros por meio de dispositivos eletrônicos, o que os leva a ganhar um status elevado entre os pares e chegar ao sucesso e poder.

Em uma palavra: pode-se afirmar que, em situações de bullying e cyberbullying, há ausência da preservação de aspectos morais, ou seja, são notadas as evidências de ausência de culpa ou vergonha morais quando os autores se desengajam e, portanto, pouco legitimam para si conteúdos como a justiça, a misericórdia, o respeito ou a generosidade.

\section{Considerações finais}

Ainda que nossa inspiração tenha sido pensar a relação entre a falta de conteúdos morais e a participação efetiva de um personagem - o agressor - em situações de bullying, temos a convicção de que a superação desse problema inclui, de qualquer forma, todos os envolvidos nessas violências. Assim, uma vez que a violência destrói o indivíduo, o mais importante para preveni-la é a criação de vínculos entre os membros de uma comunidade. Vínculos em que a prática do diálogo e do respeito a sentimentos e a possibilidade de tomada de decisões estejam presentes e possam favorecer a dinâmica respeitosa entre aqueles que estão na escola também para aprender a se relacionar com o outro. Certamente, combater a cultura individualista e competitiva da sala de aula, por meio de propostas de trabalho cooperativo e atividades que promovam a interação positiva entre os pares, colabora para uma educação para a tolerância.

É preciso que aqueles que educam tenham a certeza de que a convivência ética prevê, nos casos de bullying, um olhar atento a quem sofre, a quem assiste, mas também a quem 
agride, como um sujeito que precisa de nossa ajuda para experimentar situações em que possa perceber-se membro de um grupo por outros valores hierarquizados em sua personalidade que não a intolerância ou a falta de respeito.

Certamente, as consequências não serão menos graves para esses meninos: jovens agressores que, na vida adulta, estarão fadados à solidão, porque ninguém suporta o tempo todo alguém que submete o outro às suas vontades. Contudo, o conjunto da obra é preciso ser levado em consideração: jovens vítimas continuarão inexpressivas, submissas, depressivas, e jovens testemunhas não se indignarão com os problemas de violência que veem, porque lhes é natural.

Em suma, o impacto dessas consequências nos aproxima de experiências importantes para a superação e prevenção dessa violência. A literatura nos indica a urgência e a necessidade de investimentos em formas de protagonismo juvenil no contexto escolar. Lembra Torrego (2013) do quanto o homem é um ser social e, dessa forma, necessita da cooperação entre todos para que possa alcançar seus objetivos e aspirações para a vida. Assim, segundo ele, as relações entre os iguais são fundamentais para que se melhore as competências sociais, exercitando a negociação, a criação de normas justas e os questionamentos do que é injusto. O autor então propõe o trabalho sistemático com os sistemas de apoio entre iguais, em que a ajuda prestada atinge também os que prestam o serviço, tanto quanto aqueles que recebem a ajuda, considerando exatamente os que menos o sabem fazer.

As propostas de protagonismo infantojuvenil das quais participam autores, vítimas e espectadores de bullying têm sido indicadas pelas pesquisas atuais como a grande possibilidade de que cada um dos envolvidos supere sua condição moral (DEL BARRIO et al., 2011).

Cabe ressaltar a necessidade de que tenhamos leis antibullying e políticas públicas que reiterem a importância de ações que sejam planejadas, intencionais e sistematizadas de um conteúdo que não pode definitivamente ser menosprezado ou esquecido pela escola: a convivência ética. Quando elaborados os "planos de convivência", tem-se um impacto nas escolas para a prevenção da violência. Isso porque pesquisas atuais (CARNOY, 2003; CASSASUS, 2002; FERNÁNDEZ, 2008) já destacaram que o desempenho escolar que tanto buscamos está diretamente relacionado com a qualidade do clima escolar e, portanto, também da convivência na escola. Segundo Fernández García (2008), aprende-se mais e melhor quando há "um clima positivo no qual se desenvolvem pessoas com mais valores de 
solidariedade, tolerância e respeito e quando se constroem espaços sociais de responsabilidade e autorregulação dentro de um marco de consenso às normas estabelecidas".

Parece óbvio, portanto, que o ponto de chegada não pode ser encontrado sem um ponto de partida: não se combate o bullying senão por um projeto construído coletivamente em que a convivência MORAL seja tema. Diferentes países cuja cultura educacional tem se desvencilhado das cenas de violência que comumente chegam a nossos olhos e ouvidos conseguiram organizar em suas comunidades educativas um sistema integrado para esse fim, planejando, elegendo responsáveis, estudando e destinando tempo físico e psicológico a pensar ações concretas que sistematizem a construção dos valores que tanto desejamos.

\section{REFERÊNCIAS}

ALMEIDA, A.; CORREIA, I.; MARINHO, S. Moral disengagement, normative beliefs of peer group, and attitudes regarding roles in bullying. Journal of School Violence, v. 9, n. 1, p. 23-36, 2010.

ANG, R. P.; GOH, D. H. Cyberbullying among adolescents: The role of affective and cognitive empathy, and gender. Child Psychiatry and Human Development, v. 41, p. 387-397, 2010.

ARAÚJO, U. F. Um estudo da relação entre o ambiente cooperativo e o julgamento moral na criança. Campinas, 1993. Dissertação de mestrado - Faculdade de Educação, Unicamp.

ARISTÓTELES. Ética a Nicômaco. São Paulo: Nova Cultural, 1991.

AVILÉS MARTÍNEZ, J. M. Representaciones acerca del maltrato entre iguales, atribuciones emocionales y percepción de estrategias de cambio a partir de un instrumento narrativo: SCAN-BULLYING. Infancia y Aprendizaje, v. 26, n. 1, p. 63-78, 2003.

AVILÉS MARTÍNEZ, J. M. Diferencias de atribuición causal en el bullying entre sus protagonistas. Revista Electrónica de Investigación Psicoeducativa, n. 9, v. 4 (2), p. 201-220, 2006.

AVILÉS MARTÍNEZ, J. M. Victimización percibida y bullying. Factores diferenciales entre víctimas. Boletín de Psicología, n. 95, p. 7-28, 2009a.

AVILÉS MARTÍNEZ, J. M. Ciberbullying: Diferencias entre el alumnado de secundaria. Boletín de Psicología, n. 96, p. 79-96, 2009b. 
AVILÉS MARTÍNEZ, J. M. Éxito escolar y ciberbullying. Boletín de Psicología, n. 98, p. 73-85, marzo 2010.

BANDURA A.; BARBARANELLI C.; CAPRARA G. V.; PASTORELLI C. Mechanisms of moral disengagement in the exercise of moral agency. Journal of Personality and Social Psychology, 71, 364-374, 1996.

BANDURA, A. Desengajamento moral na perpetração de desumanidades. In: BANDURA, A.; AZZI, R. G.; TOGNETTA, L. R. P. (Orgs.). Desengajamento moral: teoria e pesquisa a partir da teoria social cognitiva. Campinas, SP: Mercado de Letras, 2015. p. 19-64.

BAUMAN, S. Cyberbullying in a rural intermediate school: An exploratory study. Journal of Early Adolescence, v. 30, p. 803-833, 2010.

BAUMAN, Z. 44 cartas do mundo líquido moderno. Rio de Janeiro: Zahar, 2010.

CAPRARA, G. V.; PASTORELLI, C.; BANDURA, A. La misura del disimpegno morale in età evolutiva. Età Evolutiva, v. 51, p. 18-29, 1995.

CARNOY, M.; GOVE, A. K.; MARSHALL, J. H. As razões das diferenças de desempenho acadêmico na América Latina: dados qualitativos do Brasil, Chile e Cuba. Revista Brasileira de Estudos Pedagógicos, v. 84, n. 206/207/208, jan./dez. 2003, p. 7-33.

COLBY, A.; DAMON, W. The uniting of self and morality in the development of extraordinary moral commitment. In: NOAM, G. C.; WREN, E. (Orgs.). The Moral Self. Cambridge: The Mit Press, 1993. p. 149-174.

COWIE, H.; MYERS, C. Bullying in universities and colleges: Cross-national perspectives. New York: Routledge, 2016.

DEL BARRIO, C.; MARTÍN, E.; ALMEIDA, A. Del maltrato y otros conceptos relacionados con la agresión entre escolares, y su estudio psicológico. Infancia y Aprendizaje, v. 26, n. 1, p. 9-24, 2003.

DEL BARRIO, C. et al. Representaciones acerca del maltrato entre iguales, atribuciones emocionales y percepción de estrategias de cambio a partir de un instrumento narrativo: SCAN-Bulling. Infancia y Aprendizaje, v. 26, n. 1, p. 63-78, 2003.

DEL BARRIO, C. et al. Contribuyendo al bienestar emocional de los compañeros: evaluación del Programa Compañeros Ayudantes em um instituto madrileno. European Journal of Education and Psychology, v. 4, n. 1, p. 5-17, 2011.

DeVRIES, R.; ZAN, B. A ética na educação infantil. Porto Alegre: Artes Médicas, 1998. FANTE, C.; PEDRA, J. A. Bullying escolar: perguntas e respostas. Porto Alegre: Artmed, 2008. 
FERNÁNDEZ GARCÍA, I. Los programas de ayuda para la mejora de la convivencia en instituciones educativas. Bordón, v. 60, n. 4, p. 137-150, 2008.

GERBINO, M.; ALESSANDRI, G.; CAPRARA, G. V. Valori, disimpegno morale e violenza nei giovani adulti. Età Evolutiva, v. 90, p. 88-96, 2008.

GIBBS, J. C. Moral development and reality: Beyond the theories of Kohlberg and Hoffman. Thousand Oaks, CA: Sage Publications Inc, 2010.

GINI, G. Social cognition and moral cognition in bullying: What's wrong? Aggressive Behavior, v. 32, p. 528-539, 2006.

GINI, G.; POZZOLI, T.; HAUSER, M. Bullies have enhanced moral competence to judge relative to victims, but lack moral compassion. Personality and Individual Differences, v. 50, n. 5, p. 603-608, Apr. 2011.

KANT, I. Fundamentação da metafísica dos costumes. São Paulo: Abril Cultural, 1974.

KNAFO, A. Authoritarians, the next generation: Values and bullying among adolescent children of authoritarian fathers. Analyses of Social Issues and Public Policy, v. 3, p. 199-204, 2003.

KNAFO, A.; DANIEL, E.; KHOURY-KASSABRI, M. Values as protective factors against violent behavior in Jewish and Arab high schools in Israel. Child Development, v. 79, n. 3, p. 652-667, 2008.

LA TAILLE, Y. Vergonha, a ferida moral. Petrópolis, RJ: Vozes, 2002.

LA TAILLE, Y. Moral e ética: dimensões intelectuais e afetivas. Porto Alegre: Artmed, 2006.

LEPRE, R. M. Por que estudar a moralidade humana e seus possíveis desdobramentos? In: MARTINS, R. A.; CRUZ, L. A. N. (Orgs.). Desenvolvimento sócio moral e condutas de risco em adolescentes. Campinas, SP: Mercado de Letras, 2015. p. 9-24.

MENESINI, E.; NOCENTINI, A.; CAMODECA, M. Morality, values, tradicional bullying, and cyberbullying in adolescence. British Journal of Developmental Psychology, v. 31, p. 1-14, Oct. 2011.

MENIN, M. S. S. et al. Injustiças na escola: concepções de alunos. Cadernos de Educação, Pelotas, RS, n. 31, p. 85-113, jul.-dez. 2008.

OBERMANN, M. Moral disengagement among bystanders to school bullying. Journal of School Violence, v. 10, n. 3, p. 239-257, 2011.

OLWEUS, D. Bullying at school. What we know and what we can do. Blackwell: Oxford and Cambridge, 1993.

OLWEUS, D. Bully/victim problems in school: Facts and intervention. European Journal 
of Psychology of Education, v. XII, n. 4, p. 495-510, 1997.

PEPLER, D. et al. Developmental trajectories of bullying and associated factors. Child Development, v. 79, n. 2, p. 325-338, 2008.

PIAGET, J. O juízo moral na criança. São Paulo: Summus, 1994. (Publicado originalmente em 1932).

PORNARI, C. D.; WOOD, J. Peer and cyber aggression in secondary school students: The role of moral disengagement, hostile attribution bias, and outcome expectancies.

Aggressive Behavior, v. 36, p. 81-94, 2010.

SCHWARTZ, S. H. Universals in the content and structure of values: Theoretical advances and empirical tests in 20 countries. Advances in Experimental Social Psychology, New York, v. 25, p. 1-65, 1992.

SONJA, P.; GUTZWILLER-HELFENFINGER, E. Cyberbullying and traditional bullying in adolescence: differential roles of moral disengagement, moral emotions, and moral values. European Journal of Developmental Psychology, v. 9, n. 2, p. 195-209, 2012.

SUTTON, J.; SMITH, P. K.; SWETTENHAM, J. Social cognition and bullying: Social inadequacy or skilled manipulation? British Journal of Developmental Psychology, v. 17, p. 435-450, 1999.

THOMBERG, R.; JUNGERT, T. Bystander behavior in bullying situations: basic moral sensitivity, moral disengagement and defender self-efficacy. Journal of Adolescence, $v$. 23, p. 34-85, 2012.

TOGNETTA, L. R. P. A construção da solidariedade e a educação do sentimento na escola: uma proposta de trabalho com as virtudes numa visão construtivista. Campinas, SP: Mercado de Letras, 2003.

TOGNETTA, L. R. P. Um olhar sobre o bullying escolar e sua superação: contribuições da Psicologia Moral. In: TOGNETTA, L. R. P.; VINHA, T. P. Conflitos na instituição educativa: perigo ou oportunidade? Contribuições da Psicologia. Campinas, SP: Mercado de Letras, 2011.

TOGNETTA, L. R. P.; AVILÉS MARTíNEZ, J. M.; ROSÁRIO, P. J. S. L. F. Bullying, un problema moral: representaciones de sí mismo y desconexiones morales. Revista de Educación, p. 9-34, jul.-sept. 2016.

TOGNETTA, L. R. P.; BOZZA, T. L. Cyberbullying: um estudo sobre a incidência do desrespeito no ciberespaço e suas relações com as representações que adolescentes têm de si. Nuances, v. 23, n. 24, p. 164-180, 2012.

TOGNETTA, L. R. P.; LA TAILLE, Y. A formação de personalidades éticas:

representações de si e moral. Psicologia: Teoria e Pesquisa, Brasília, v. 24, n. 2, p. 181188, 2008. 
TOGNETTA, L. R. P.; ROSÁRIO, P. Bullying e autorregulação: um estudo sobre o fenômeno à luz da Psicologia Moral entre estudantes do estado de São Paulo. Relatório de pós-doutorado, 2012 (texto não publicado).

TOGNETTA, L. R. P.; VINHA, T. P. Valores em crise: o que nos causa indignação. In: LA TAILLE, Y.; MENIN, M. S. de S. (Orgs.). Crise de valores ou valores em crise? Porto Alegre: Artmed, 2009.

TOGNETTA, L. R. P.; VINHA, T. P. Bullying e intervenção no Brasil: um problema ainda sem solução. In: $8^{\circ}$ CONGRESSO NACIONAL DE PSICOLOGIA DA SAÚDE: SAÚDE, SEXUALIDADE E GÊNERO. Actas do ISPA - Instituto Universitário. Lisboa, Portugal. Anais eletrônicos, 2010a. p. 487-494.

TOGNETTA, L. R. P.; VINHA, T. P. Até quando? Bullying na escola que prega a inclusão social. Revista Educação, Santa Maria, v. 35, n. 3, p. 449-464, set.-dez. 2010 b.

TOGNETTA, L. R. P. et al. Características das relações entre pares e sua relação com o fenômeno bullying. In: GUIMARAES, Á. M.; PACHECO E ZAN, D. D. Caderno de resumos do I Seminário Violar: Problematizando Juventudes na Contemporaneidade. Campinas, SP: FE/Unicamp, 2010.

TORREGO, J. C. (Coord.). La ayuda entre iguales para mejorar la convivencia escolar: manual para la formación de alumnos ayudantes. Madrid: Narcea, 2013.

TREMBLAY, P. F.; EWARD, L. A. The Buss and Perry Aggression Questionnaire and its relations to values, the Big Five, provoking hypothetical situations, alcohol consumption patterns, and alcohol expectancies. Personality and Individual Differences, v. 38, p. 337346, 2005.

TURIEL, E. Social regulations and domains of social concepts. In: DAMON, W. (Ed.). Nex directions for child development, VI. San Francisco: Jossey-Bass, 1978.

TURNER, R. M. Moral disengagement as a predictor of bullying and aggression: Are there gender differences? (Tesis doctoral no published). University of Nebraska-Lincoln. Resumen de la Tesis en la Internacional Sección A: Humanities and Social Sciences, 69 (7-A), 2609, 2009.

VÁSQUEZ, A. S. Ética. Rio de Janeiro: Civilização Brasileira, 1997.

VINHA, T. P. O educador e a moralidade infantil numa visão construtivista. Campinas, SP: Mercado de Letras, 2000.

WACHS, S. Moral disengagement and emotional and social difficulties in bullying and cyberbullying: differences by participant role. Emotional \& Behavioral Difficulties, v. 17, n. 3-4, p. 347-360, 2012. 


\section{Como referenciar este artigo}

TOGNETTA, Luciene Regina Paulino et al. Bullying e cyberbullying: quando os valores morais nos faltam e a convivência se estremece. Revista Ibero-Americana de Estudos em Educação, Araraquara, v. 12, n. 3, p. 1880-1900, jul-set/2017. Disponível em: <http://dx.doi.org/10.21723/riaee.v12.n.3.2017.10036>. E-ISSN: 1982-5587.

Submetido em: 30/03/2017

Aprovação final em: 09/07/2017 